\title{
1 The influence of different wind and wave conditions on 2 the energy yield and downtime of a Spar-buoy floating

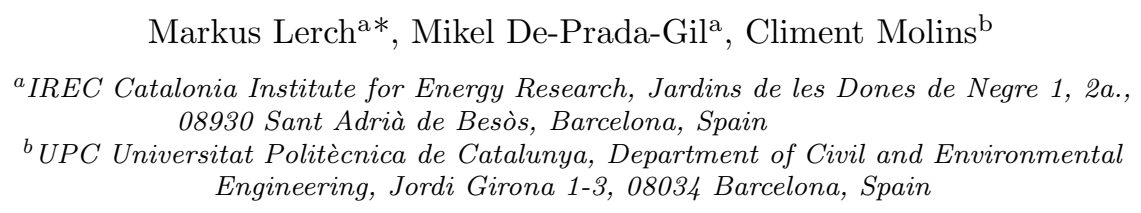

\section{Abstract}

Preprint submitted to Renewable Energy Journal

November 29, 2018

*E-mail address: mlerch@irec.cat Tel.: +34 933562615 Fax.: +34 933563802 Corresponding author (Markus Lerch) 


\section{Introduction}

Floating substructures for offshore wind turbines are a promising solution that has emerged in recent years. With lower constraints to water depths and soil conditions, floating offshore wind turbines (FOWT) can be placed in deep waters where the current technology based on bottom-fixed substructures is not feasible from a technical and economic perspective [1]. Moreover, FOWT enable to access remote offshore locations, where higher wind speeds are available and larger capacity factors can be reached [2]. As several FOWT concepts have been successfully tested in wave tanks and prototypes have been proven in open seas, floating offshore wind is now reaching a pre-commercial phase where the first floating wind turbine array has been constructed in European waters [3]. This transition increases the need for comprehensive tools that allow to model the complete system and to predict its behavior as well as to assess the performance for different locations. There exist software packages that allow to model the behavior of wind turbines with a high fidelity and complexity level. However, such programs require a detailed description of the model and a high computational time.

The main objective of this paper is to study the influence of met-ocean conditions of different sites on the energy yield and downtime of a FOWT. A simplified numerical model with reduced degrees of freedom has been developed, which allows capturing the main motions of the FOWT and to predict the energy generation considering the dynamic behavior of the system and the environment of the site. The model is developed as part of the tool FOWAT (Floating Offshore Wind Assessment Tool), which has been created in the H2020 LIFES50plus project to assess both economically and technically floating offshore wind farms [4]. The purpose of the model developed in this paper is to contribute with a more realistic annual energy production profile, which can be used for the calculation of the levelized cost of energy. The model considers in the calculation of the energy yield the characteristic motions of the FOWT as well as the downtime due to exceeding operating limits. 
Not many research papers could be found that investigate the influence of the dynamic response of a FOWT on the long-term energy yield for different offshore sites. The reason might be that many of the FOWT concepts are still in the early development phase and, therefore, the main research effort is given on the correct modeling and experimental testing with different load cases. For instance, a comprehensive comparison of different aero-hydro-servo-elastic modeling codes has been performed in the OC3 (Offshore Code Comparison Collaboration) research project [5] and several studies have been performed on the modeling of the hydrodynamic and aerodynamic response of a FOWT $[6,7,8,9]$. Besides that, the influence of individual degrees of freedom on the power characteristics has been investigated for example in surge [10], pitch [11] and yaw [12]. In 2015, Martini et al. [13] have studied by statistical means the performance of a semi-submersible FOWT considering 20 years of met-ocean data. Hub acceleration and platform pitch motions have been defined as the most relevant operating parameters, which are also applied in this work as selected threshold limits. The model developed in the present paper is intended to assess the performance of a Spar-buoy concept at different offshore sites. In addition, a sensitivity analysis of certain threshold limits is carried out to study the impact on the capacity factor and downtime of the FOWT. The model can be useful for early feasibility studies or at the design state and can be of great interest for different stakeholders such as project developers, substructure designers, wind farm operators or investors.

This paper is organized as follows. Section 2 presents the FOWT concept considered in this study. In Section 3, the methodologies that are used in the numerical model are presented. In Section 4, the developed model is validated against an existing software solution by performing a dynamic analysis of the selected FOWT concept and comparing the results. In Section 5, the performance of the floating offshore wind turbine is presented for three offshore sites. In addition, a sensitivity analysis on the hub acceleration and platform pitch as operating limits is performed. Section 6 finishes the paper with the main conclusions. 


\section{Floating wind turbine concept}

The floating wind turbine system that is modeled is the OC3-Hywind concept [14]. It is based on the Spar-buoy developed by Statoil and slightly adapted by NREL for modeling purposes in the OC3 project. It supports the NREL 5MW offshore wind turbine [15]. The FOWT is illustrated in Fig. 1. The concept was chosen for the availability of data, the simplicity of the geometry and the relevance of the technology on the market since it is one of the most promising concepts for floating offshore wind [2]. The 5MW NREL wind turbine is a threebladed horizontal-axis wind turbine as defined by Jonkman et al. [15] and is used in this study considering the modifications introduced for the floating platform by Jonkman [14]. The mooring system of Statoil's Hywind concept consists of three catenary mooring lines attached to the substructure via a delta connection. A simplification has been made for the OC3-Hywind concept by removing the delta connection and adding a yaw spring to achieve proper overall stiffness. Furthermore, the multisegment lines are replaced by an equivalent homogenous line with weighted-average properties and damping is neglected [14]. The most relevant properties of the Spar-buoy FOWT are presented in Table 1.

Table 1. Floating wind turbine main properties [15, 14].

\begin{tabular}{lllll}
\hline \multicolumn{2}{l}{ Turbine and tower properties } & \multicolumn{2}{l}{ Spar-buoy substructure properties } & \multicolumn{2}{l}{ Mooring system properties } \\
\hline Rated power & $5 \mathrm{MW}$ & Total draft below SWL & $120 \mathrm{~m}$ & Number of mooring lines \\
Gearbox & multiple-stage & Elevation to substructure top & $10 \mathrm{~m}$ & Angle between lines \\
Cut-in, rated, cut-out & $3,11.4,25 \mathrm{~m} / \mathrm{s}$ & Depth to top of taper & $4 \mathrm{~m}$ & Depth to fairleads \\
Rotor diameter & $126 \mathrm{~m}$ & Depth to bottom of taper & $12 \mathrm{~m}$ & Depth to anchors \\
Hub height & $90 \mathrm{~m}$ & Substructure diameter above & $6.5 \mathrm{~m}$ & Radius to fairleads \\
Tower base & $10 \mathrm{~m}$ & Substructure diameter below & $9.4 \mathrm{~m}$ & Radius to anchors \\
RNA mass & $350.0 \mathrm{t}$ & Substructure mass & $7466.3 \mathrm{t}$ & Wet mooring line weight \\
Tower mass & $249.7 \mathrm{t}$ & & & Unstreched line length \\
\hline
\end{tabular}




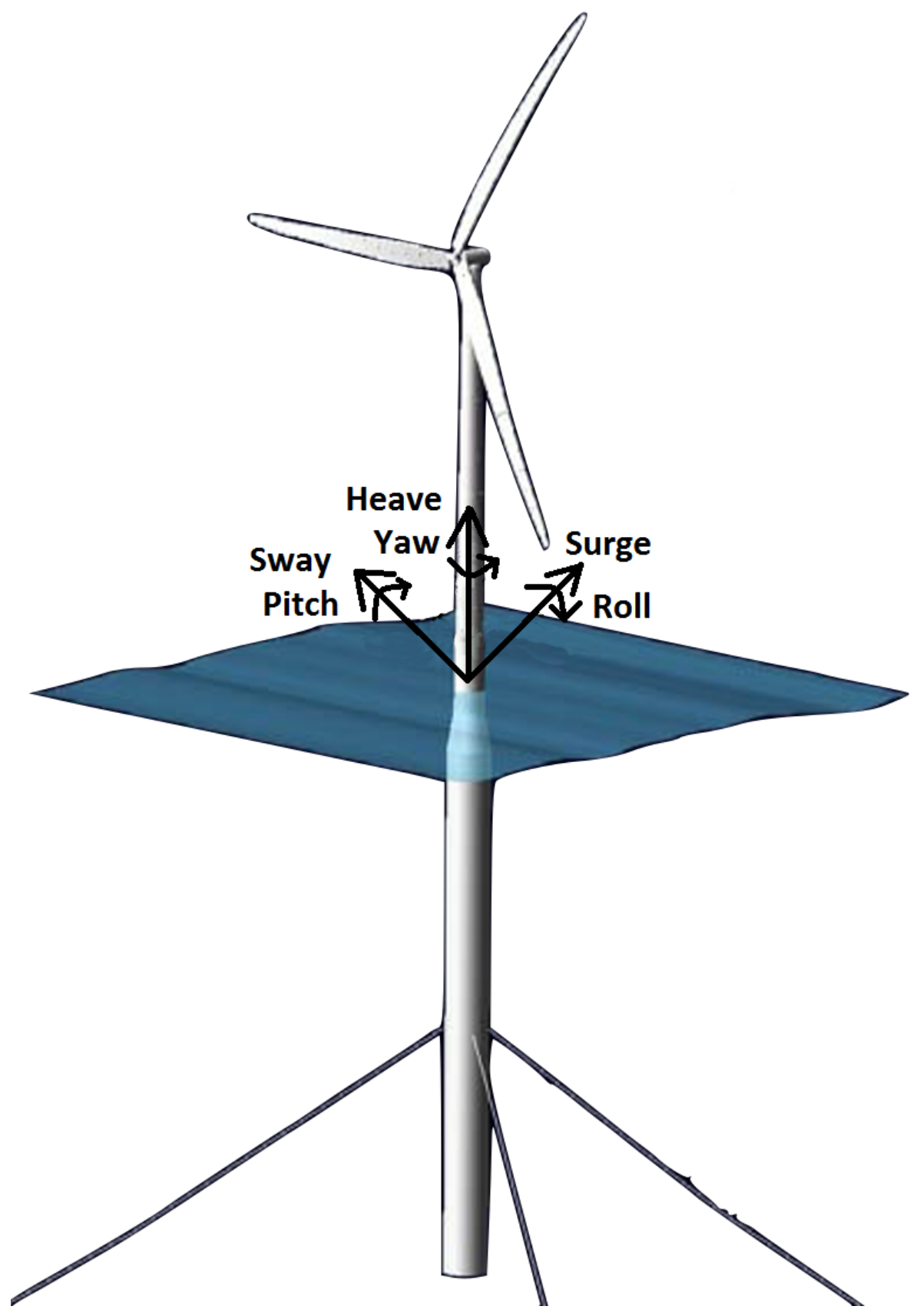

Fig. 1. OC3-Hywind concept illustration [14]. 


\section{Methodology}

\subsection{Model description}

There are two fundamental approaches that can be followed to model the structural behavior of a FOWT [16]. The first approach considers the FOWT as a single rigid body subject to environmental loads and neglects structural deflections by assuming infinite stiffness. This allows for a significant simplification of the model. The second approach is the finite element method, which discretizes the structure in a number of finite elements and takes into account the structural flexibility [17]. Since the structural response and motions are mainly dominated by rigid body motions rather than elastic deformation, the first approach is considered to model the FOWT with enough accuracy [18]. The dynamic analysis of a FOWT is performed by the model by solving the equation of motion in time domain. The equation of motion for a floating structure is given by Equation 1, which is based on Newton's second law of motion [16].

$$
(M+A) \ddot{x}(t)+B \dot{x}(t)+(C) x(t)=F_{\text {ext }}(t)
$$

The motion vector $\mathrm{x}$ represents the displacements in each degree of freedom (DOF). The derivatives represent the corresponding velocities and accelerations. For a FOWT there are typically six rigid-body degrees of freedom as illustrated in Fig. 1. Due to the symmetry of the Spar-buoy concept and in order to simplify the model only the motions on the XZ-plane will be considered. Hence, the number of degrees of freedom is reduced to three: surge, heave and pitch. $M$ and $A$ represent the mass and added mass of the FOWT. $B$ is the damping and $C$ the hydrostatic stiffness. All those before mentioned are $3 \times 3$ matrices according to the selected degrees of freedom and including coupling terms. $F_{\text {ext }}$ represents the vector of all external forces and moments acting on the FOWT [16]. In order to solve Equation 1 all the loads and forces have to be identified. The modeling of the external forces is presented in Section 3.2 and the methodology for computing the structural properties of the left side of the equation is presented in Section 3.3. 
Once the equation of motion is completely defined, it is written in the statespace form in order to eliminate the second order differential equations and ode45 function from MATLAB is used to solve it.

\subsection{Load description}

The forces that act on the FOWT consist of aerodynamic, hydrostatic and hydrodynamic loads as well as the mooring system. Wind and waves are considered as main environmental loads in this study. However, there are other conditions such as currents, tides, seismic activity or ice that can impact the performance of a FOWT depending on the location, but are out of scope of this paper [19].

\subsubsection{Aerodynamics}

The aerodynamic loading on a wind turbine depends mainly on the wind velocity and the rotor characteristics. The wind thrust force acting on the FOWT is given as

$$
F_{\text {wind }}=\frac{1}{2} \rho_{\mathrm{a}} \pi R_{\text {rotor }}^{2} C_{\mathrm{T}} v_{\text {rel }}^{2}
$$

where $\rho_{a}$ represents the air density, $R_{\text {rotor }}$ is the radius of the rotor, $C_{T}$ the thrust coefficient and $v_{r e l}$ the relative wind velocity. The relative wind velocity is the velocity seen by the rotor at hub height and can be obtained as follows

$$
v_{\text {rel }}=v_{\text {wind }}-v_{\text {hub }}
$$

where $v_{\text {wind }}$ represents the incoming wind speed and $v_{h u b}$ is the hub velocity due to the motions of the substructure. The wind velocity is considered as uniform and one-directional as seen by the hub. The wind force acting on the tower has been neglected. The thrust coefficient is, in general, a function of the blade tip-speed ratio and the blade pitch angle [20]. This approach has been used in Section 3.4 to calculate the power generation. In regard to the modeling of the structural behavior, a simplified approach was used by considering the dependence of the thrust coefficient only on the wind speed as follows 


$$
C_{\mathrm{T}}=\left[\begin{array}{cc}
C_{\mathrm{T} 0} & \text { if } v_{\text {rel }} \leq v_{\text {rated }} \\
C_{\mathrm{T} 0} e^{\left(-\mathrm{a}\left(\mathrm{v}_{\text {rel }}-\mathrm{v}_{\text {rated }}\right)^{\mathrm{b}}\right)} & \text { if } v_{\text {rel }}>v_{\text {rated }}
\end{array}\right],
$$

where $C_{T 0}$, a and b are constants with the values $0.75,0.25$ and 0.86 , respectively [21]. This approach allows to maximize the thrust force up to rated wind speed $v_{\text {rated }}$ by keeping $C_{T}$ constant. After rated wind speed, the thrust coefficient is exponentially reduced. In addition, a control system is modeled, which limits the $C_{T}$ variation rate. This simple control provides the system with enough time to include the tower oscillation motion and avoid negative damping, which has occurred in studies performed by Nielsen et al. [22] for the Hywind Spar-buoy concept.

The motions of a floating wind turbine have additional effects on the aerodynamics compared to bottom-fixed offshore wind turbines (BOWT). In this study, two effects have been included. The first is that the motions of the floating wind turbine provoke an additional mean platform tilt angle as outlined in Section 3.4 and the second is the relative wind velocity as described above. Further effects such as the potential occurrence of vortex ring states, time-varying rotor induction, skewed inflow or blade-vortex interactions [16] are not considered and beyond the scope of this paper. In particular, the interaction between the wind turbine rotor and its wake is a complex phenomenon that requires the application of advanced modeling tools such as free wake vortex methods or computational fluid dynamic simulations [23]. A comprehensive aerodynamic simulation of the floating wind turbine, however, has not been the objective of this study.

\subsubsection{Hydrostatics}

The hydrostatic loads on the platform refer to the effect of having a submerged body in water and its motions. It can be divided into an undisturbed buoyancy force and a restoring term due to the platform movements. The restoring term is the hydrostatic stiffness $C$ of Equation 1 and its computation is defined in Section 3.3. 
The buoyancy force is a vertical force directed upwards and according to Archimedes' principle possesses a value equal to the volume of fluid displaced by the body and can be obtained by

$$
F_{\text {buoy }}=\rho_{\mathrm{w}} g V \text {, }
$$

where $\rho_{w}$ is the water density, $g$ the gravitational acceleration and $V$ the submerged volume of the Spar [24]. The force that balances the buoyancy is the weight and is obtained by considering the total mass $m_{t}$ of the FOWT [14] as

$$
F_{\mathrm{G}}=-m_{\mathrm{t}} g .
$$

\subsubsection{Hydrodynamics}

Morison equation has been applied to calculate the hydrodynamic loads acting on the FOWT. It is one of the widely used methods for slender structures like the Spar and aims to address viscous effects as well as inertial loads by an empirically derived formula [25]. Equation 7 presents the Morison equation in conjunction with strip theory by dividing the structure in discrete elements of $d z$. The total force is obtained by integrating $d F$ over the length of the Spar [24].

$$
\begin{aligned}
d F_{\mathrm{h}} & =\frac{1}{2} \rho_{\mathrm{w}} C_{\mathrm{d}} D d z\left|v_{\mathrm{r}}\right| v_{\mathrm{r}}+C_{\mathrm{a}} \rho_{\mathrm{w}} A(z) d z a_{\mathrm{r}}+A(z) d z \rho_{\mathrm{w}} a_{\mathrm{W}} \\
v_{\mathrm{r}} & =v_{\mathrm{W}}-v_{\mathrm{B}}
\end{aligned}
$$

$C_{a}$ and $C_{d}$ are the hydrodynamic added mass and viscous-drag coefficients and their values for the OC3-Hywind concept are 0.969954 and 0.6, respectively [14]. The model assumes a constant added mass and drag coefficient since the considered Spar concept has demonstrated a low variation across oscillation frequencies and high Reynolds numbers in most environmental conditions [14]. The term $D d z$ is the frontal area of the strip and $A d z$ is the displaced volume of fluid for the corresponding strip. $v_{r}$ is the relative velocity between the water particle velocity $v_{W}$ and the velocity of the body $v_{B}$. 
The corresponding accelerations are $a_{r}$ and $a_{W}$ [24]. The equation does not account for the hydrodynamic heave force experienced by the FOWT. The heave force can be approximated by the change of the hydrostatic pressure caused by the variation of wave elevation $\eta$ at the water-plane area $A_{w p}$ as [14]

$$
F_{\mathrm{p}}=\rho_{\mathrm{w}} g \eta A_{\mathrm{wp}} .
$$

\subsubsection{Mooring system}

There exist several methods to model the mooring loads depending on the level of accuracy and the information required as well as the computational complexity needed as outlined by Chakrabarti [26]. The applied method follows the quasi-static analysis approach, which considers the offset of the floating structure caused by wave-induced motions in time domain and the computation of the non-linear catenary stiffness at each offset within the equation of motions [26].

The mooring line is taken as a continuous cable with homogeneous properties and elasticity is considered to provide the line profile. Forces arising from inertia, viscous drag, internal damping, bending and torsion are neglected [27]. The quasi-static model is applied, because it provides a reasonable approximation of the mooring load and a simple calculation methodology compared with a fully dynamic model. The catenary mooring is modeled as a single line. The mooring line is fixed by the anchor at the bottom at one end. The other end of the line is attached to the structure by the fairlead. As the structure is being displaced, the fairlead position moves at a height $h$ and length $l$ and provokes a resulting horizontal and vertical force at the fairlead from the mooring load. Equation 24 and 10 are used to obtain the fairlead forces for a fully suspended mooring line $[28]$.

$$
l=\frac{X}{w}\left(\ln \left(\frac{Z}{X}+\sqrt{1+\left(\frac{Z}{X}\right)^{2}}\right)-\ln \left(\frac{Z-w L}{X}+\sqrt{1+\left(\frac{Z-w L}{X}\right)^{2}}\right)\right)+\frac{X L}{E A}
$$




$$
h=\frac{X}{w}\left(\sqrt{1+\left(\frac{Z}{X}\right)^{2}}-\sqrt{1+\left(\frac{Z-w L}{X}\right)^{2}}\right)+\frac{1}{E A}\left(Z L-\frac{w L^{2}}{2}\right)
$$

$X$ is the horizontal and $Z$ the vertical component of the fairlead force. The unstretched line length is given as L and w represents the weight per unit length of the mooring line in the water. EA is the cross-section axial stiffness. The system of nonlinear equations is solved for a range of possible displacements of the fairlead and by using the solver fsolve from MATLAB. When the vertical force $\mathrm{Z}$ is less than the total weight of the cable (i.e., $Z \leq w L$ ), then a portion of the mooring line will rest on the seabed and Equations 11 and 12 have to be used [28].

$$
\begin{gathered}
l=\frac{X}{w}\left(\ln \left(\sqrt{1+\left(\frac{Z}{X}\right)^{2}+\frac{Z}{X}}\right)\right)+\frac{X}{E A} L+L-\frac{Z}{w} \\
h=\frac{X}{w}\left(\sqrt{1+\left(\frac{Z}{X}\right)^{2}}-1\right)+\frac{Z^{2}}{2 w E A}
\end{gathered}
$$

The total mooring load on the structure is obtained by considering the fairlead displacement of all three mooring lines and computing the sum of all fairlead forces.

\subsection{Structural properties}

The global mass matrix is determined by [25]

$$
M=\left[\begin{array}{ccc}
m_{\mathrm{t}} & 0 & m_{\mathrm{t}} z_{\mathrm{CoM}} \\
0 & m_{\mathrm{t}} & -m_{\mathrm{t}} x_{\mathrm{CoM}} \\
0 & -m_{\mathrm{t}} x_{\mathrm{CoM}} & I_{\mathrm{yy}}
\end{array}\right] .
$$

The non-zero off-diagonal terms result from a slight displacement $x_{C o M}$ of the center of mass to the origin [29]. The added mass is additional mass that the structure appears to have when it is accelerated relative to the surrounding water. 
In general, the added mass is dependent on the wave frequency and also on the size and shape of the floating structure. However, in the developed model a constant added mass matrix is considered. Strip theory is used to calculate the added mass for each DOF using added mass coefficients of 2 dimensional sections and integrating over the length [18]. The added mass matrix is modeled as

$$
A=\left[\begin{array}{ccc}
\int_{z_{\mathrm{bot}}}^{0} \rho_{\mathrm{w}} C_{\mathrm{a}} A(z) d z & 0 & \int_{z_{\mathrm{bot}}}^{0} \rho_{\mathrm{w}} C_{\mathrm{a}} A(z) z d z \\
0 & \frac{2}{3} \rho_{\mathrm{w}} \pi R^{3} & 0 \\
\int_{z_{\mathrm{bot}}}^{0} \rho_{\mathrm{w}} C_{\mathrm{a}} A(z) z d z & 0 & \int_{z_{\mathrm{bot}}}^{0} \rho_{\mathrm{w}} C_{\mathrm{a}} A(z) z^{2} d z
\end{array}\right],
$$

where $C_{a}$ represents the added mass coefficient and $A(z)$ the cross-sectional area of the Spar structure. The diameter of the Spar changes with the hight and has to be considered in the calculation of the cross-sectional area. As explained in Section 3.2.3, damping due to radiation is neglected in Morison equation. However, Jonkman [14] recommends to add linear damping to capture correctly the response of the OC3-Hywind concept to hydrodynamic loads. The additional damping for surge and heave included as damping matrix is

$$
B=\left[\begin{array}{ccc}
1.000 e^{5} \mathrm{~N} \mathrm{~s} / \mathrm{m} & 0 & 0 \\
0 & 1.300 e^{5} \mathrm{~N} \mathrm{~s} / \mathrm{m} & 0 \\
0 & 0 & 0
\end{array}\right]
$$

The hydrostatic stiffness represents the restoring term as effect of the substructure movements in the water in heave and pitch direction. There is no hydrostatic restoring term in surge or in coupled motions. The variation in heave of the submerged volume will create a force equal in magnitude to the volume of fluid displaced. The restoring moment will arise with the pitch motion from the horizontal displacement of the gravity and buoyancy centers and the water-plane area inertia effects. The restoring torque is written as a sum of the three contributions [30]. 


$$
C=\left[\begin{array}{ccc}
0 & 0 & 0 \\
0 & \rho_{\mathrm{w}} g A_{\mathrm{wp}} & 0 \\
0 & 0 & \rho_{\mathrm{w}} g I_{\mathrm{wp}}+\rho_{\mathrm{w}} g V z_{\mathrm{CoB}}-m_{\mathrm{t}} g z_{\mathrm{CoM}}
\end{array}\right]
$$

$$
K=\left[\begin{array}{ccc}
K_{11} & 0 & K_{31} \\
0 & K_{33} & 0 \\
K_{13} & 0 & K_{55}
\end{array}\right]
$$

268

The stiffness parameters represent mean values obtained from the nonlinear quasi-static model. They are used for the computation of the natural frequencies of the FOWT and for comparison of the developed model with FAST. However, in the dynamic model the nonlinear mooring load is considered as an external force for the computation of the Morison equation. Based on the previously defined matrices, the natural frequencies and periods of the FOWT can be obtained from the homogeneous undamped equation of motion as [16]

$$
(M+A) \ddot{x}+(C+K) x=0 .
$$

The solution is considered to be as

$$
x=x_{0} e^{\mathrm{ift}},
$$

where $x_{0}$ is the vector of amplitudes and $\mathrm{f}$ is the natural frequency for each DOF. By computing the second derivative and replacing it on Equation 18, the eigenvalue problem is obtained and can be solved as

$$
C(M+A)^{-1}-f^{2} I=0 .
$$




\subsection{Power generation}

The power generated by the FOWT can be calculated by Equation 21 taking into account the rotor swept area $A_{\text {rotor }}$, the power coefficient $C_{p}$ and the wind speed $v_{\text {wind }}$ at hub height. The power coefficient depends on the blade tip-speed ratio $\lambda$ and the blade pitch angle $\beta[20]$.

$$
P_{\mathrm{FOWT}}=\frac{1}{2} \rho_{\mathrm{a}} A_{\text {rotor }} C_{\mathrm{p}}(\lambda, \beta) v_{\text {wind-tilted }}^{3}
$$

Two considerations have been included in the power equation of the FOWT in contrast to a BOWT. The first is that the motions of the FOWT provoke an additional mean platform tilt angle. This causes the rotor to be slightly tilted against the inflow wind velocity $v_{\text {wind }}$. This effect is taken into account in the power calculation by reducing the inflow wind velocity by the pitch angle $\theta$ of the structure as follows [16]

$$
v_{\text {wind-tilted }}=v_{\text {wind }} \cos (\theta) \text {. }
$$

The second consideration is that the model takes into account the relative wind velocity in the wind force computation of the FOWT as defined by Equations 2 and 3 .

\subsection{Energy generation}

The annual energy generation of the FOWT can be obtained by

$$
E_{\mathrm{FOWT}}=\sum P_{\mathrm{j}, \mathrm{k}} * H_{\mathrm{j}, \mathrm{k}} * 8760
$$

where $P_{j, k}$ is the power obtained for a specific met-ocean condition, defined by a certain wind speed $j$ and a particular wave height $k$. The occurrence probability per year of this particular met-ocean condition is considered by $H_{j, k}$.

\section{Model validation}

The developed model described previously is validated in this section by performing a dynamic analysis on the OC3-Hywind Spar-buoy concept and comparing the results to the ones obtained in the OC3 project by using the FAST software. 


$$
\left[\begin{array}{lll}
7.98 e^{6} \mathrm{~kg} & 0 & -4.94 e^{8} \mathrm{~kg} \mathrm{~m} \\
0 & 2.23 e^{4} \mathrm{~kg} & 0 \\
-4.94 e^{8} \mathrm{~kg} \mathrm{~m} & 0 & 3.97 e^{10} \mathrm{~kg} \mathrm{~m}^{2}
\end{array}\right]
$$

Added mass computed by FOWAT

$\left[\begin{array}{lll}8.07 e^{6} \mathrm{~kg} & 0 & -6.29 e^{8} \mathrm{~kg} \mathrm{~m} \\ 0 & 8.07 e^{6} \mathrm{~kg} & 1.12 e^{5} \mathrm{~kg} \mathrm{~m} \\ -6.29 e^{8} \mathrm{~kg} \mathrm{~m} & 1.12 e^{5} \mathrm{~kg} \mathrm{~m} & 6.80 e^{10} \mathrm{~kg} \mathrm{~m}^{2}\end{array}\right]$

Mass computed by FAST

The mass matrix calculated by the developed model agrees well with the one obtained by FAST $[14,29]$. The obtained added mass matrix is presented next and compared to the results from FAST for zero frequency [14].

$$
\left[\begin{array}{lll}
8.00 e^{6} \mathrm{~kg} & 0 & -4.90 e^{8} \mathrm{~kg} \mathrm{~m} \\
0 & 2.00 e^{4} \mathrm{~kg} & 0 \\
-4.90 e^{8} \mathrm{~kg} \mathrm{~m} & 0 & 3.90 e^{10} \mathrm{~kg} \mathrm{~m}^{2}
\end{array}\right]
$$

Added mass by FAST approximated
307

308

The mooring stiffness matrix obtained by FOWAT is shown next. The accuracy of the developed model is quite high for the mooring stiffness calculation in comparison to FAST. 


$$
\left[\begin{array}{lll}
4.12 e^{4} \mathrm{~N} / \mathrm{m} & 0 & -2.82 e^{6} \mathrm{~N} / \mathrm{rad} \\
0 & 1.19 e^{4} \mathrm{~N} / \mathrm{m} & 0 \\
-2.82 e^{6} \mathrm{~N} / \mathrm{m} & 0 & 3.11 e^{8} \mathrm{~N} \mathrm{~m} / \mathrm{rad}
\end{array}\right]\left[\begin{array}{lll}
4.12 e^{4} \mathrm{~N} / \mathrm{m} & 0 & -2.82 e^{6} \mathrm{~N} / \mathrm{rad} \\
0 & 1.19 e^{4} \mathrm{~N} / \mathrm{m} & 0 \\
-2.82 e^{6} \mathrm{~N} / \mathrm{m} & 0 & 3.11 e^{8} \mathrm{~N} \mathrm{~m} / \mathrm{rad}
\end{array}\right]
$$

Mooring stiffness computed by FOWAT Mooring stiffness computed FAST

310

$$
\left[\begin{array}{lll}
0 & 0 & 0 \\
0 & 3.34 e^{5} \mathrm{~N} / \mathrm{m} & 0 \\
0 & 0 & -5.01 e^{9} \mathrm{~N} \mathrm{~m} / \mathrm{rad}
\end{array}\right]
$$

Hydrostatic stiffness by FOWAT

$$
\left[\begin{array}{lll}
0 & 0 & 0 \\
0 & 3.33 e^{5} \mathrm{~N} / \mathrm{m} & 0 \\
0 & 0 & -4.99 e^{9} \mathrm{~N} \mathrm{~m} / \mathrm{rad}
\end{array}\right]
$$

Hydrostatic stiffness by FAST

Table 2. Natural frequencies.

\begin{tabular}{lccc}
\hline & Surge $(\mathrm{Hz})$ & Heave $(\mathrm{Hz})$ & Pitch $(\mathrm{Hz})$ \\
\hline FAST & 0.008 & 0.032 & 0.034 \\
FOWAT & 0.008 & 0.033 & 0.033 \\
Difference & 0.000 & 0.001 & 0.001 \\
\hline
\end{tabular}

According to the results shown in Table 2, the surge frequency obtained from the FOWAT model matches the value calculated in the OC3 report by Jonkman et al. [32]. The frequency in heave is slightly higher than the reference one and the pitch is slightly lower. However, the differences are smaller than $3 \%$ and the accuracy of the developed model is seen to be sufficient for the purpose of this study.

\subsection{Dynamic analysis}

In this section, the dynamic response of the FOWT to three load cases (LC) is computed. The LC are based on the OC3 Phase IV study [5] where different modeling codes have been compared. 


\subsubsection{Load case 1}

The first load case applied on the FOWT is used to obtain the static equilibrium conditions when the system has no initial displacement and is not excited by any load. Fig. 2 shows the time response of the FOWT to the load case for the 3 degrees of freedom considered in this study.
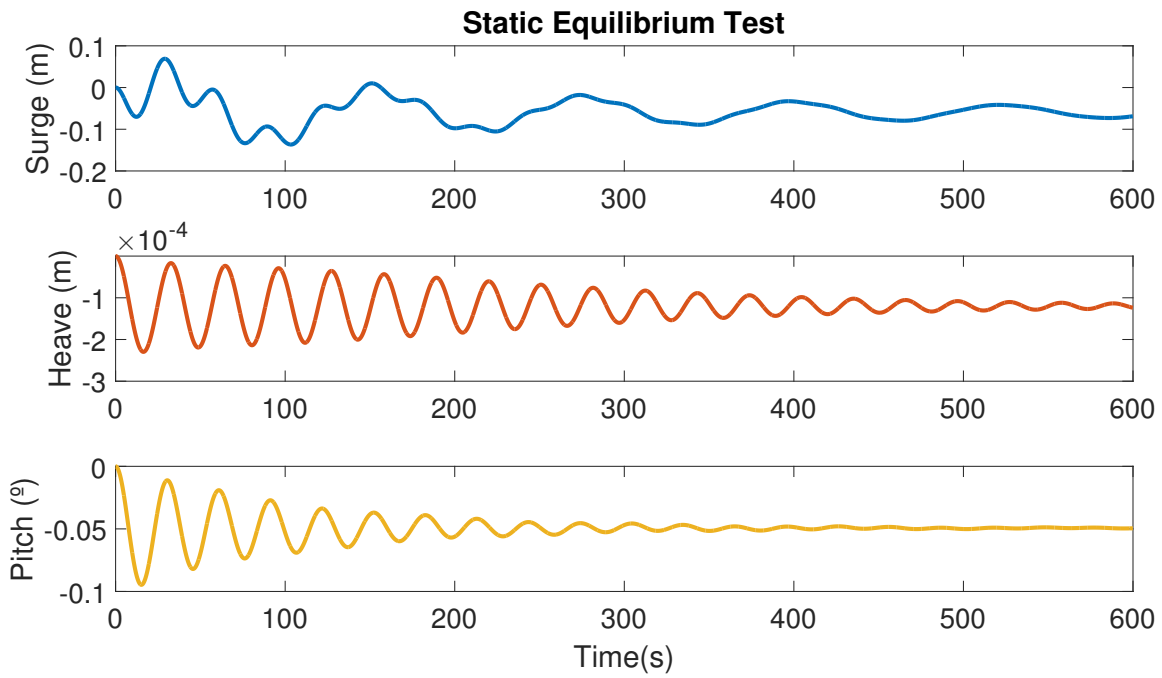

Fig. 2. Stability test from LC 1 .

The final stability position of the FOWT achieved by using both the model FOWAT and the software FAST is displayed in Table 3.

Table 3. Final stability position.

\begin{tabular}{lccc}
\hline & Surge $(\mathrm{m})$ & Heave $(\mathrm{m})$ & Pitch $\left(^{\circ}\right)$ \\
\hline FAST & -0.079 & -0.000 & -0.066 \\
FOWAT & -0.068 & -0.000 & -0.049 \\
Difference & 0.011 & 0.000 & 0.017 \\
\hline
\end{tabular}

It can be observed that in both models the stability position of the FOWT is different to zero, which is based on a small initial displacement of the center of mass of the substructure. However, both models respond correctly to the load case by converging to an equilibrium point. 
4.2.2. Load case 2

The second LC is used to analyze the behavior of the FOWT based on the excitation by a steady wind force of $8 \mathrm{~m} / \mathrm{s}$ and regular airy waves of $6 \mathrm{~m}$ height and 10 s period. The time response for the non-transient part is shown in Fig. 3.
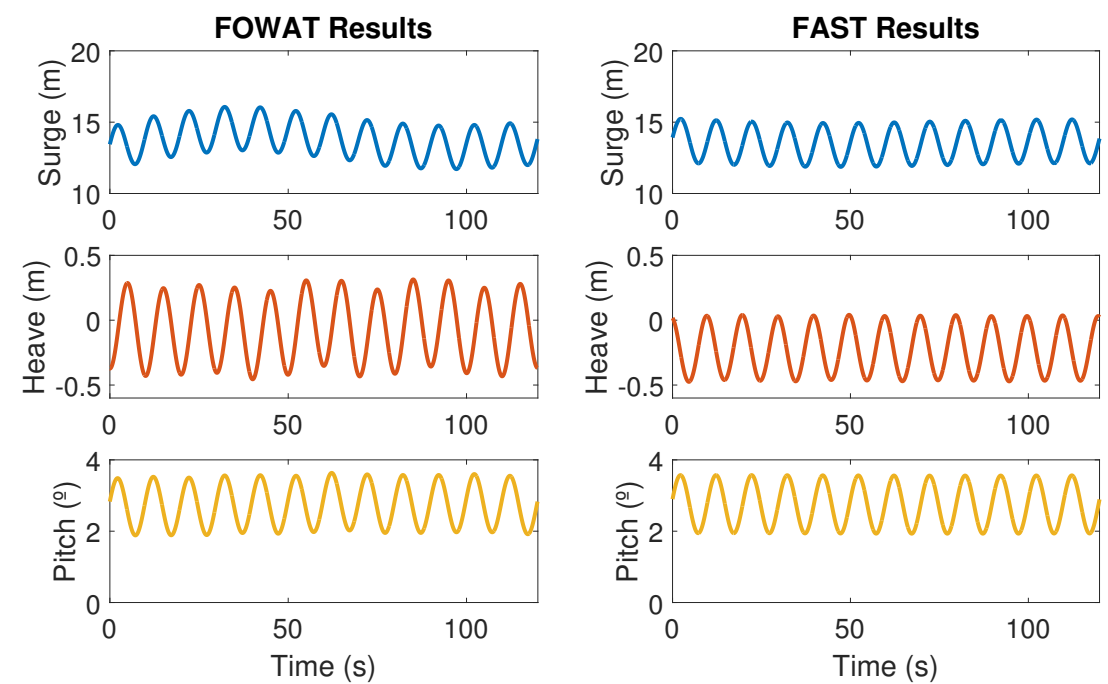

Fig. 3. Non-transient response.

It can be observed that the system oscillates around the equilibrium position and with the wave frequency in all degrees of freedom. The oscillation with the natural frequencies is also visible. Besides that, it can be seen that the wind force generates an offset in both the surge and pitch, which causes the equilibrium point to be different than zero for these two DOFs. The average values for the non-transient part obtained with the developed model and FAST are presented in Table 4. As it can be seen, the calculated values are close to the ones obtained with FAST, which allows to conclude that the aerodynamic effect is correctly captured by the model. 
Table 4. Mean displacements.

\begin{tabular}{lccc}
\hline & Surge $(\mathrm{m})$ & Heave $(\mathrm{m})$ & Pitch $\left(^{\circ}\right)$ \\
\hline FAST & 13.54 & -0.22 & 2.75 \\
FOWAT & 13.68 & -0.07 & 2.74 \\
Difference & 0.14 & 0.15 & 0.01 \\
\hline
\end{tabular}

4.2.3. Load case 3

LC 3 is used to study the effect of irregular waves and turbulent wind based. JONSWAP spectrum is considered to create the irregular wave profile with a significant wave height of $6 \mathrm{~m}$ and a peak-spectral wave period of 10s. The turbulent wind, based on the Kaimal spectrum, has a mean wind speed equal to the rated speed of $11.4 \mathrm{~m} / \mathrm{s}$ and a turbulence intensity of 0.14 . Since the irregular wave profile is a superposition of waves with different frequencies, the response of the FOWT is shown as statistical parameters in Table 5.

Table 5. Response comparison between FOWAT and FAST for LC 3.

\begin{tabular}{llccccc}
\hline & & Wind $(\mathrm{m} / \mathrm{s})$ & Wave $(\mathrm{m})$ & Surge $(\mathrm{m})$ & Heave $(\mathrm{m})$ & Pitch $\left(^{\circ}\right)$ \\
\hline \multirow{2}{*}{ Minimum } & FOWAT & 6.28 & -4.54 & 14.67 & -0.83 & 0.18 \\
& FAST & 6.60 & -5.84 & 11.38 & -1.07 & 1.33 \\
Mean & FOWAT & 11.11 & 0.01 & 23.79 & -0.21 & 4.74 \\
& FAST & 11.43 & 0.01 & 21.19 & -0.47 & 4.25 \\
Maximum & FOWAT & 16.16 & 4.73 & 31.78 & 0.23 & 7.12 \\
& FAST & 17.37 & 4.73 & 31.13 & 0.11 & 6.26 \\
Standard & FOWAT & 1.46 & 1.36 & 3.84 & 0.17 & 1.16 \\
Deviation & FAST & 1.96 & 1.49 & 4.09 & 0.22 & 0.84 \\
\hline
\end{tabular}
accelerations.

For this LC the range of motions shows a good agreement with the mean values calculated by FAST. A slight over- or underestimation is observable for some of the minimum and maximum values, which could be due to the statistical estimation of the loads. The studied load cases have confirmed that the implified model accounts for the main effects of the FOWT for the motions and rere 


\subsubsection{Computation time}

The computation times by FAST (v8.16.00a-bjj) and FOWAT are measured and compared for the three load cases discussed in the Sections 4.2.1 to 4.2.3. The comparison is carried out using a computer with an Intel Core i5-6500 processor with $3.2 \mathrm{GHz}, 8 \mathrm{~GB}$ memory and Windows 10 operating system. The results are presented in Table 6 .

Table 6. Comparison of computation times between FAST and FOWAT.

\begin{tabular}{llcccc}
\hline & & \multicolumn{2}{c}{ Computation time } & \multicolumn{2}{c}{ Difference } \\
Load case & Conditions & FAST (s) & FOWAT (s) & $(\mathrm{s})$ & $(\%)$ \\
\hline LC1 & Static equilibrium & 105.6 & 7.4 & 98.2 & 93.0 \\
LC2 & $\begin{array}{l}\text { Regular wave and } \\
\text { steady wind }\end{array}$ & 157.2 & 64.6 & 92.6 & 58.9 \\
\multirow{2}{*}{ LC3 } & Irregular wave and & & & & \\
& turbulent wind & 236.4 & 121.9 & 114.5 & 48.4 \\
\hline
\end{tabular}

The results show that the simplified model FOWAT with reduced degrees of freedom provides a significant reduction in computation time for the three load cases in comparison to the more complex simulation code FAST. The simplified model, in its actual implementation in MATLAB, allows reducing about half the computation time of LC 2 and 3 and a reduction of $93 \%$ for LC 1 with an acceptable accuracy for the purpose of this study.

\subsection{Power generation performance}

The power of the FOWT has been calculated for a range of wind velocities and wave heights to simulate its specific power curve. The environmental conditions considered are regular waves and a steady wind velocity. A power curve has been computed for each of the wave heights as illustrated in Fig. 4. The power curves include the specific consideration for a FOWT as explained in Section 3.4 and the cut-in and cut-out wind speed limits of the wind turbine. 


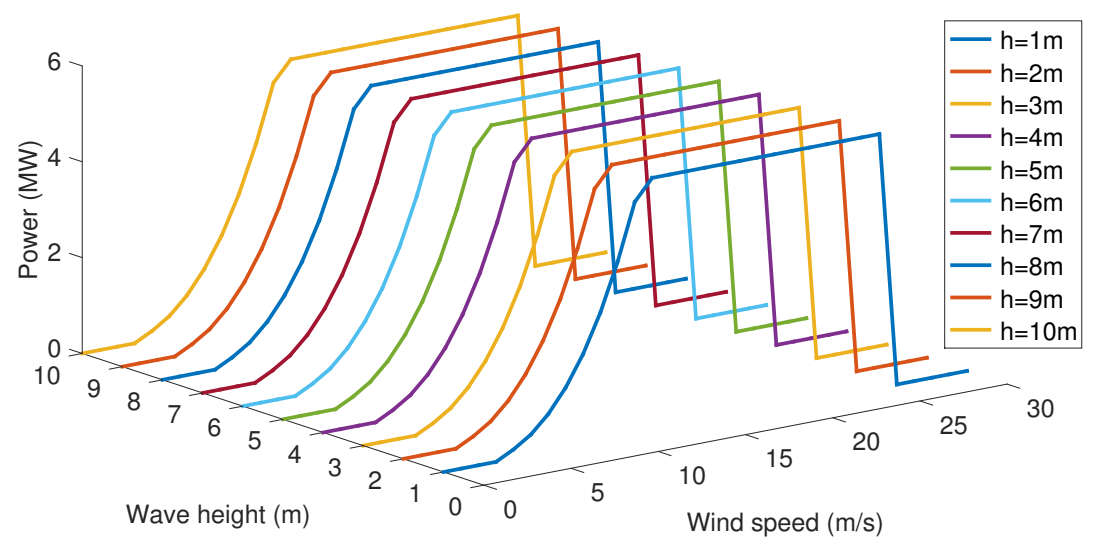

Fig. 4. Power curve of FOWT for regular waves with different wave heights (h).

It is observable that the power production behaves similarly regardless the different wave heights. This behavior is very characteristic for a Spar-type floating substructure, because the deep draft and large inertia result in low heave and pitch motions in operating conditions [34]. Fig. 5 shows the comparison between the original power curve of the NREL BOWT and the ones obtained by the FOWT.

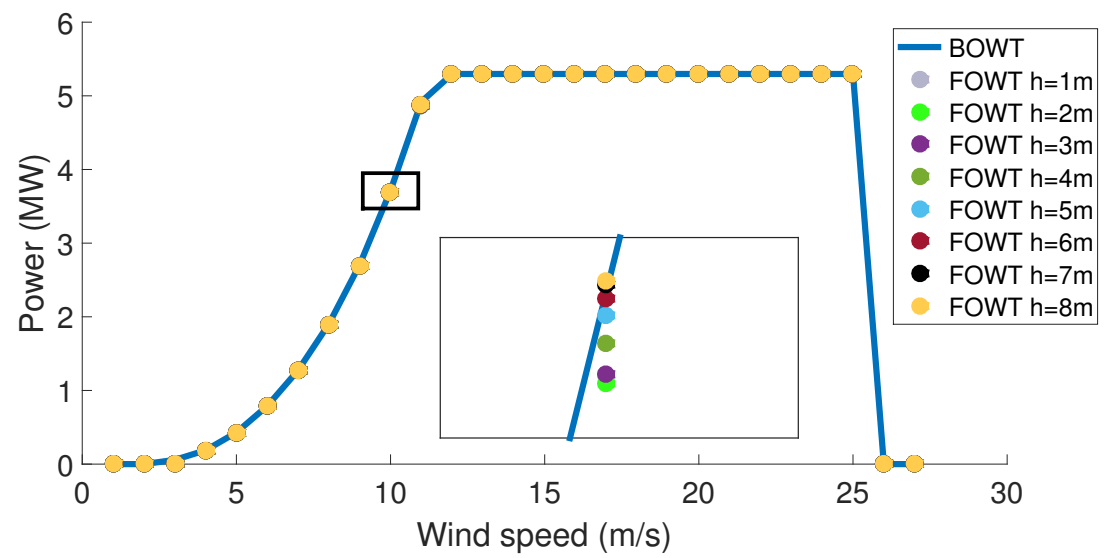

Fig. 5. Power curve comparison between BOWT (blue line) and FOWT (colored dots for regular waves with wave height $(h)$ ). 
The blue line represents the power curve of the BOWT. The dots mark the power curves of the FOWT for the different wave heights. The zoom indicates the difference according to the wave heights. As it is shown, the power curve of the FOWT is nearly identical to one obtained by the BOWT. Even the largest difference between the power curve of the BOWT and the most extreme wave is only smaller than $1 \%$. The power curve is now computed considering an environment with irregular waves and a turbulent wind velocity (Fig. 6), which represents a more realistic offshore scenario.

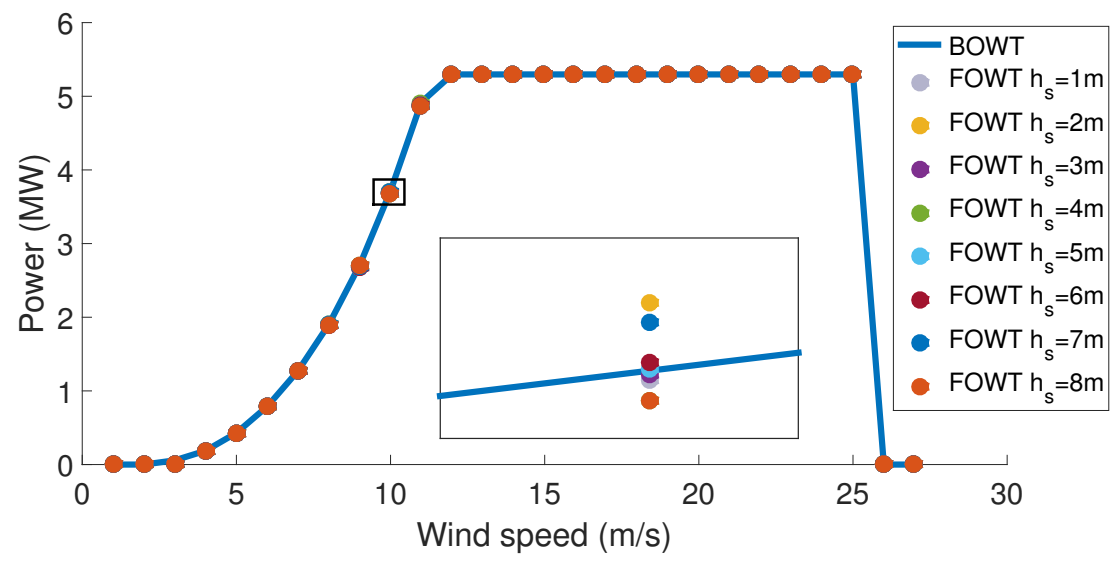

Fig. 6. Power curve comparison between BOWT (blue line) and FOWT (colored dots for irregular waves with significant wave height $\left.\left(\mathrm{h}_{\mathrm{s}}\right)\right)$.

The irregular wave and turbulent wind profiles have been generated by using JONSWAP and Kaimal spectrum, respectively. It is observable that the power curves for the FOWT follow the power curve obtained by the BOWT. The largest difference between the power curve of the BOWT and the most extreme wave is about $1.1 \%$ and is, therefore, only slightly higher than compared to the regular wave and steady wind LC. Finally, Fig. 7 shows the power coefficient obtained for the FOWT and confirms that there is a non-significant difference between the LC and the waves. 


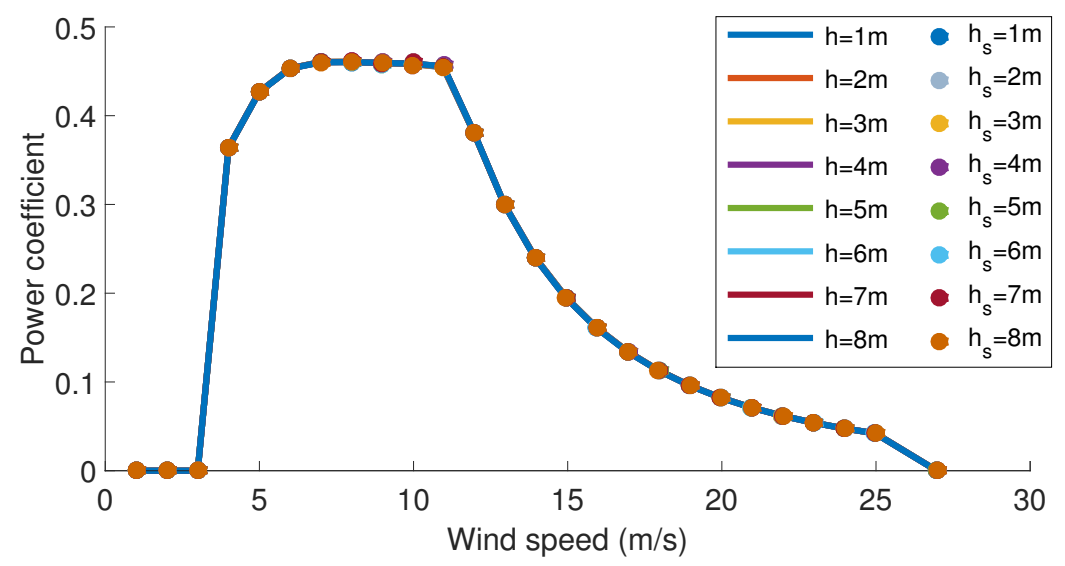

Fig. 7. Power coefficient comparison of FOWT for regular waves with wave height $(\mathrm{h})$ and irregular waves with significant wave height $\left(h_{\mathrm{s}}\right)$.

It can be concluded that the wind and wave loads have a non-significant effect on the power production performance of the OC3 Spar-buoy FOWT and that the power generation is comparable with a BOWT. This conclusion has also been demonstrated in experimental tests of the Hywind prototype in real offshore conditions [35, 33]. However, the conclusion is only valid for the specific FOWT studied in this paper. For other concepts further studies are required.

\section{Floating wind turbine performance}

\subsection{Offshore sites definition}

Three offshore locations are considered to represent different met-ocean conditions namely Costa Brava in Spain, Gulf of Maine in the USA and West of Barra in Scotland. Costa Brava is located at $42.00^{\circ} \mathrm{N} 3.50^{\circ} \mathrm{E}, 25 \mathrm{~km}$ off the city of l'Estartit in the Mediterranean Sea and has a water depth of $200 \mathrm{~m}$. The metocean conditions are moderate and the corresponding wind and wave profile is taken from the SIMAR 2126144 model point of the Spanish Port System [36]. The Gulf of Maine site is situated 65km east of Portland in the Atlantic Ocean with coordinates $43.33^{\circ} \mathrm{N} 69.27^{\circ} \mathrm{W}$ and represents medium met-ocean conditions with a water depth of $130 \mathrm{~m}$. 
West of Barra has the harshest conditions together with the highest wind speeds and is located 19km West of Barra Island in the Atlantic Ocean. The coordinates are $56.89^{\circ} \mathrm{N} 7.95^{\circ} \mathrm{W}$ and the water depth is chosen to be $150 \mathrm{~m}$. The met-ocean data for both sites was prepared within the LIFES50plus project [37]. The mooring system properties such as the line length and anchor radius are adjusted to the water depths of each site. Fig. 8 shows the combined wind-wave occurrences at each of the three sites.

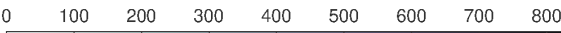

Combined wind-wave occurences ( $h /$ year)

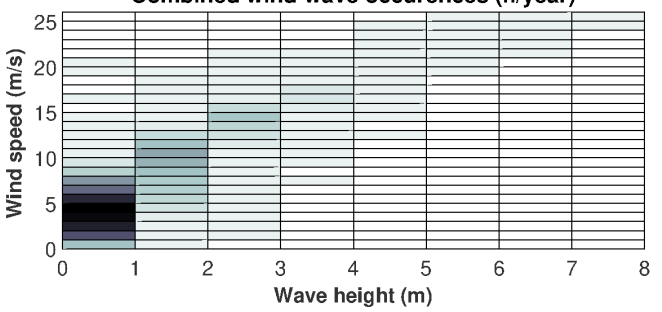

(a) Costa Brava

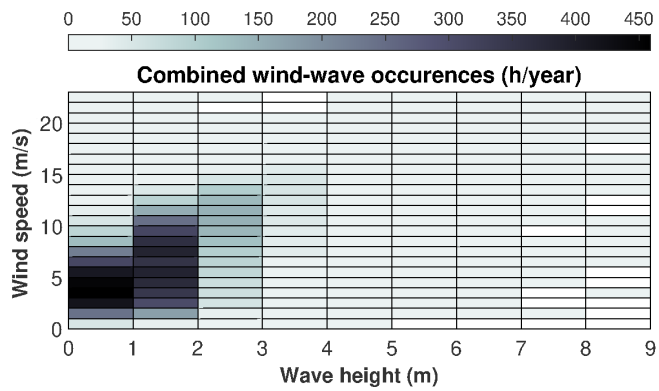

(b) Gulf of Maine

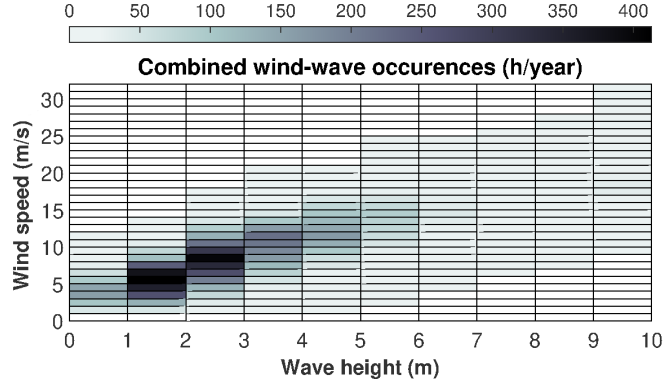

(c) West of Barra

Fig. 8. Distribution of combined wind-wave occurrences at sites (a) Costa Brava, (b) Gulf of Maine and (c) West of Barra. Wind speed measured at $10 \mathrm{~m}$ height.

The wind-wave profile of Costa Brava shows that small waves with lower wind speeds are more frequent at this site corresponding to the moderate metocean conditions. Larger waves in the range of $5 \mathrm{~m}$ to $8 \mathrm{~m}$ only occur with higher wind speeds in the range of $19 \mathrm{~m} / \mathrm{s}$ to $26 \mathrm{~m} / \mathrm{s}$, but the occurrence of those is rather rarely. The white cells represent non-occurring wind-wave combinations. 
At Gulf of Maine, a larger distribution of the wind-wave profile is present. However, the most frequent environmental conditions are between wind speeds of $1 \mathrm{~m} / \mathrm{s}$ to $11 \mathrm{~m} / \mathrm{s}$ with up to $2 \mathrm{~m}$ wave heights. At West of Barra the most frequent environmental conditions are in the range of $3 \mathrm{~m} / \mathrm{s}$ to $13 \mathrm{~m} / \mathrm{s}$ of wind speeds with wave heights of $1 \mathrm{~m}$ to $6 \mathrm{~m}$. In addition, wind speeds larger than $28 \mathrm{~m} / \mathrm{s}$ and waves higher than $9 \mathrm{~m}$ can occur, which confirm the harsh conditions at this site.

\subsection{Motion response}

The response of the FOWT is computed considering the met-ocean conditions of the three sites. The mean motions of the FOWT in surge, pitch and heave as well as the hub acceleration are presented in Fig. 9 with respect to the offshore location. The highest response for all degrees of freedom is reached at rated wind speed $(11.4 \mathrm{~m} / \mathrm{s})$. Afterwards, the applied controller acts to reduce the thrust coefficient exponentially and hence the response declines as well. The surge motion is mostly influenced by the wind. However, a slight increase of the peak surge value is also observable for increasing wave heights. At Costa Brava offshore location, the highest surge experienced is about $26 \mathrm{~m}$ for wind speeds between $13 \mathrm{~m} / \mathrm{s}$ and $14 \mathrm{~m} / \mathrm{s}$ and wave heights of $3 \mathrm{~m}$ to $4 \mathrm{~m}$. At Gulf of Maine the highest surge motion of $27.4 \mathrm{~m}$ is reached with the most extreme waves in the range of $8 \mathrm{~m}$ to $9 \mathrm{~m}$ and wind speeds between $14 \mathrm{~m} / \mathrm{s}$ and $15 \mathrm{~m} / \mathrm{s}$. The harsh environmental conditions in West of Barra result in the largest surge motion experienced by the FOWT among the three sites with $29.5 \mathrm{~m}$ for wind speeds between $18 \mathrm{~m} / \mathrm{s}$ and $21 \mathrm{~m} / \mathrm{s}$ and waves larger than $9 \mathrm{~m}$. The surge motions obtained by the model are in good agreement with the mean values of the DeepSpar presented by Karimirad et al. [38]. The pitch response of the FOWT is similar affected by the wind and wave loads as the surge. The highest value at Costa Brava site is $5.2^{\circ}$ for waves of $3 \mathrm{~m}$ to $4 \mathrm{~m}$ and wind speeds of $12 \mathrm{~m} / \mathrm{s}$ to $14 \mathrm{~m} / \mathrm{s}$. 


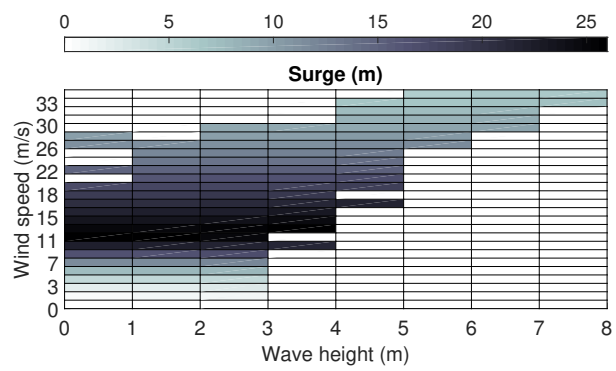

(a) Surge motion at Costa Brava

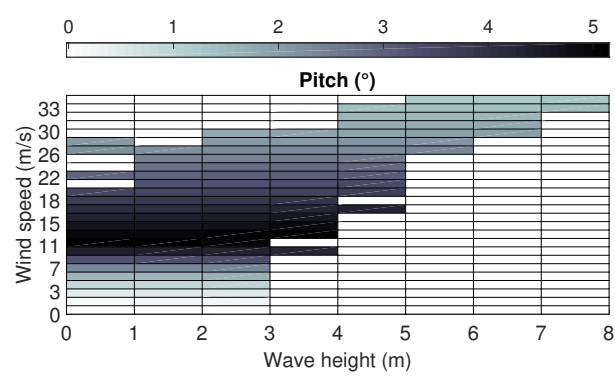

(d) Pitch motion at Costa Brava

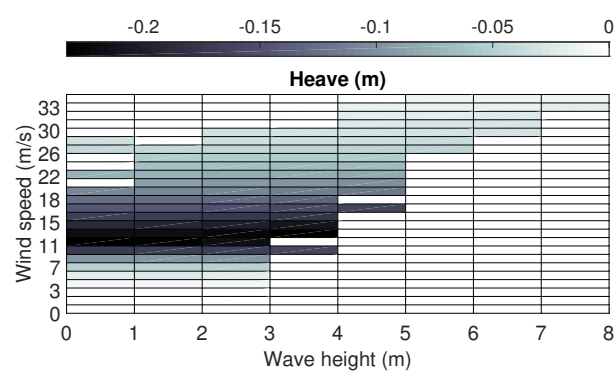

(g) Heave motion at Costa Brava

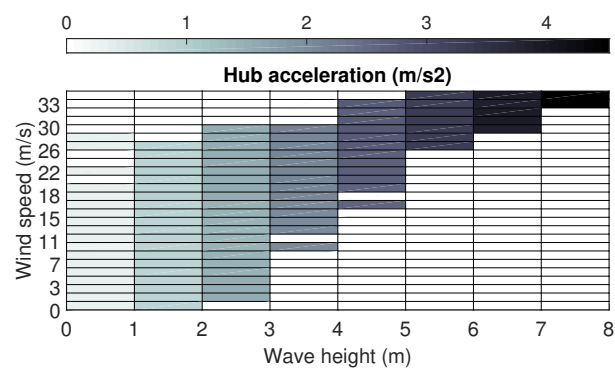

(j) Hub acceleration at Costa Brava

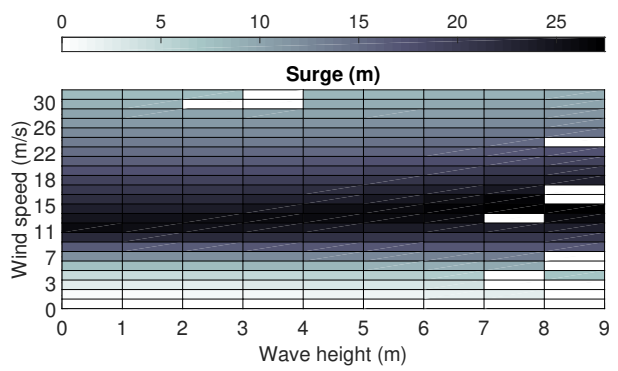

(b) Surge motion at Gulf of Maine

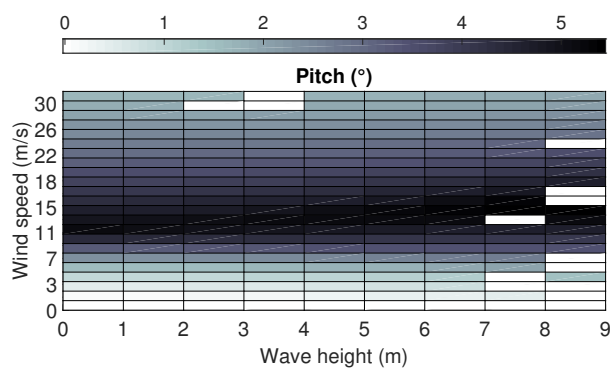

(e) Pitch motion at Gulf of Maine

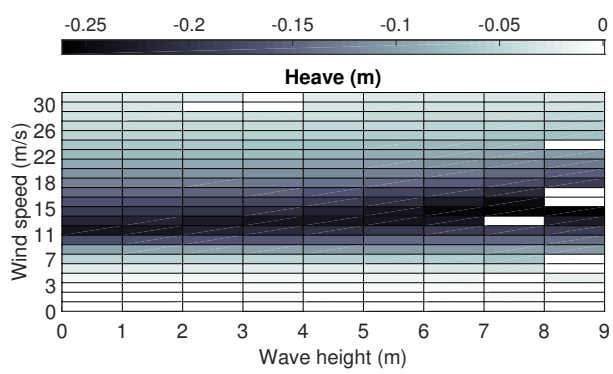

(h) Heave motion at Gulf of Maine

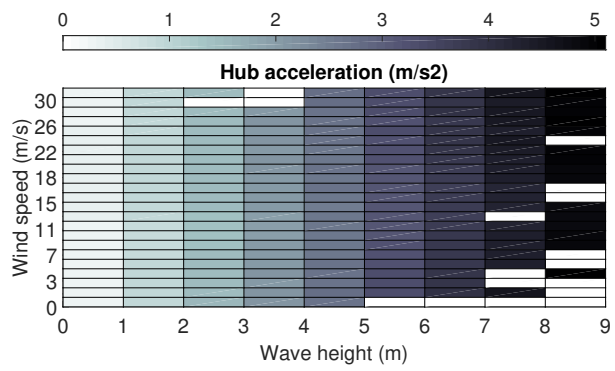

(k) Hub acceleration at Gulf of Maine

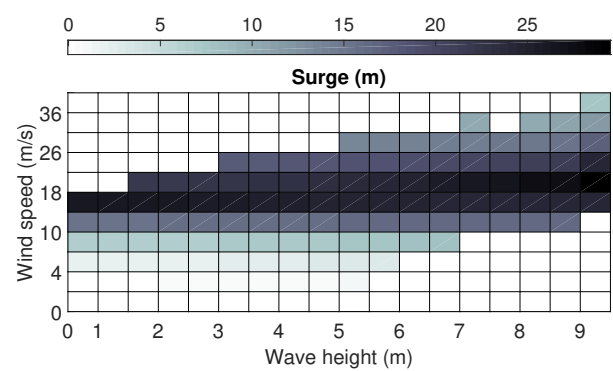

(c) Surge motion at West of Barra

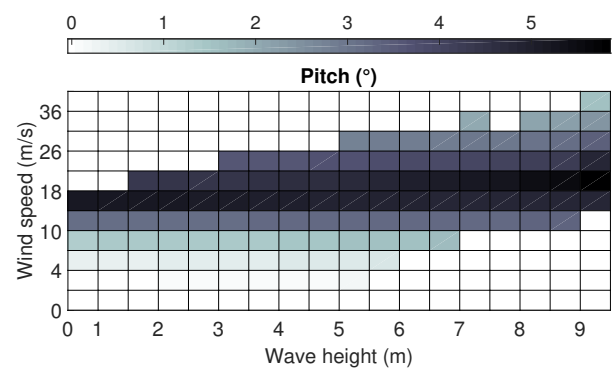

(f) Pitch motion at West of Barra

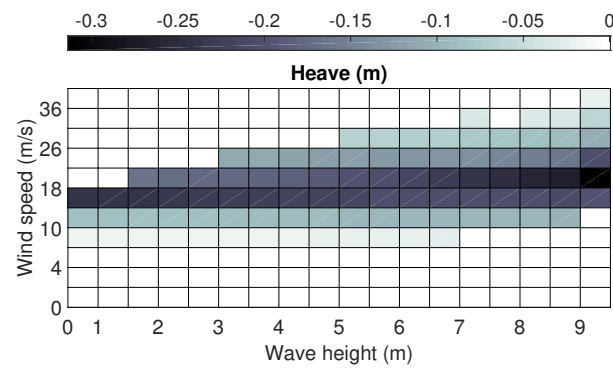

(i) Heave motion at West of Barra

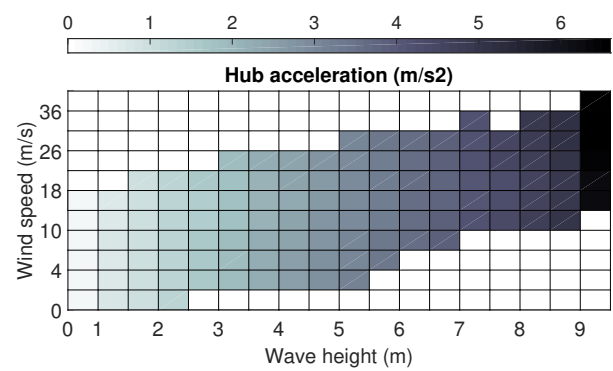

(1) Hub acceleration at West of Barra

Fig. 9. Platform motions and hub acceleration as function of wind speed (at hub) and wave height for the three offshore sites. 
The magnitude of the pitch response at Gulf of Maine is similar to Costa Brava. However, since larger waves are available at this site the maximum value increases to $5.5^{\circ}$ for wind speeds of $14 \mathrm{~m} / \mathrm{s}$ to $15 \mathrm{~m} / \mathrm{s}$ and wave heights of $8 \mathrm{~m}$ to $9 \mathrm{~m}$. The largest pitch motion is observed again at West of Barra with $5.9^{\circ}$ for the largest waves measured at this location of $9 \mathrm{~m}$ to $10 \mathrm{~m}$ and wind speeds of $18 \mathrm{~m} / \mathrm{s}$ to $21 \mathrm{~m} / \mathrm{s}$. The heave motions of the Spar are typically small since the vertical wave exciting forces are low due to the deep draft [39]. As illustrated in subplots (g) to (i), the heave mean response of the FOWT is lower than $-0.3 \mathrm{~m}$ for all three locations. The hub acceleration is mainly governed by the wave heights. In addition, the largest accelerations are experienced with a combination of highest waves and wind speeds. The maximum hub acceleration values for Costa Brava, Gulf of Maine and West of Barra are $4.5 \mathrm{~m} / \mathrm{s}^{2}, 5.1 \mathrm{~m} / \mathrm{s}^{2}$ and $6.6 \mathrm{~m} / \mathrm{s}^{2}$, respectively. Besides the before mentioned, the figure shows the distribution of possible motions at the different sites according to the existing met-ocean conditions. For instance, at Gulf of Maine a larger range of combined wind and wave heights is present, which results in a more distributed response of the FOWT from low to very high wind speeds and wave heights in contrast to the other sites.

\subsection{Energy generation}

The annual energy generated by the FOWT is plotted for each of the three sites as function of wind speed (at hub) and wave height in Fig. 10. The figure shows the characteristic energy generation profile according to the met-ocean conditions of each site. West of Barra demonstrates a larger distribution of energy generation among the available wave heights. Whereas at Costa Brava and Gulf of Maine a larger range of wind speeds is available with lower wave heights, which causes the energy generation profile to be located in the lower wave height section of the figure. Furthermore, it is observable that at West of Barra higher peak generation values are achieved based on more frequent occurrences of high wind speeds. 


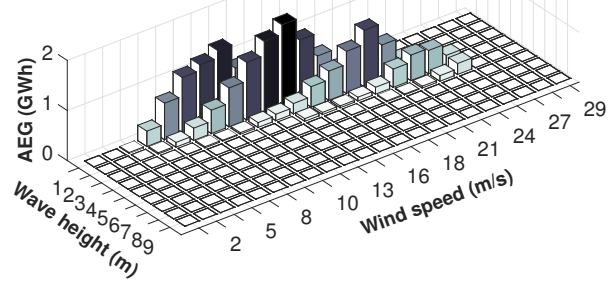

(a) Costa Brava

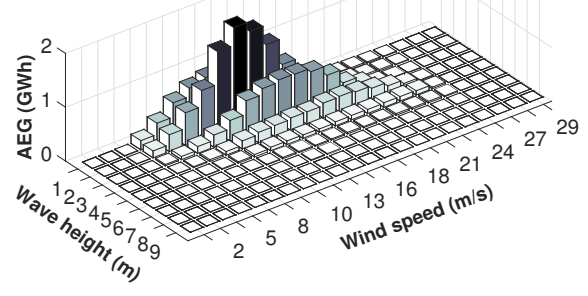

(b) Gulf of Maine

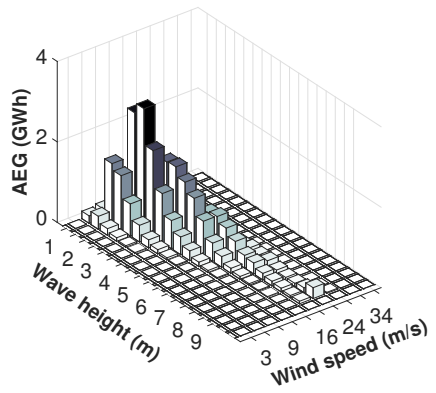

(c) West of Barra

Fig. 10. Annual energy generation profile considering the wind speed at hub and wave heights of the three offshore sites.

The total annual energy generation is presented in Table 7 for the three offshore locations and compared to a bottom-fixed offshore wind turbine with the same capacity.

Table 7. Annual energy production performance comparison.

\begin{tabular}{|c|c|c|c|c|}
\hline \multirow[b]{2}{*}{ Location } & \multicolumn{2}{|c|}{ Energy Generation (GWh) } & \multirow[t]{2}{*}{ Difference (\%) } & \multirow{2}{*}{$\begin{array}{c}\text { Capacity factor }(\% \\
\text { Floating }\end{array}$} \\
\hline & Bottom-fixed & Floating & & \\
\hline Costa Brava & 21.91 & 21.73 & 0.82 & 49.62 \\
\hline Gulf of Maine & 24.12 & 23.98 & 0.58 & 54.75 \\
\hline West of Barra & 33.32 & 33.09 & 0.69 & 75.54 \\
\hline
\end{tabular}


As it is shown in Table 7, the difference in the annual energy generation between a fixed and floating wind turbine is below $1 \%$ and thus is not very significant. In addition, a bottom-fixed offshore wind turbine would not be feasible at the three considered sites due to the large water depths. The capacity factor calculated for the FOWT at each site is also shown. It is defined in this paper as the ratio of actual energy generation to rated peak generation per year. The values demonstrate the vast potential of FOWT to be placed in locations where higher wind speeds are available and greater capacity factors can be yielded. For comparison, current bottom-fixed offshore wind farms reach capacity factors of about $30 \%$ to $50 \%$ and the first floating wind farm installed in Scottish waters has achieved a capacity factor of about $65 \%$ during the first three months of operation $[40,41]$. The high capacity factors show also that floating offshore wind could be a suitable complement to base load power generation. For example, conventional base load power plants typically possess capacity factors of about $54 \%-60 \%$ (coal) or $90 \%-92 \%$ (nuclear) [42].

\subsection{Sensitivity analysis}

In this section, a sensitivity analysis is carried out to study the effect of applying different threshold limits for the operation of the FOWT. The two parameters that are considered are the hub acceleration and the platform pitch motion, which have been defined by Martini et al. [13] as two of the most relevant operating parameters. In case the defined threshold limit is exceeded by one of the two parameters, the wind turbine is forced to shutdown and stop power generation. The performance of the FOWT under different threshold limits is evaluated in function of capacity factor and downtime as shown in Tables 8 to 10 for each of the offshore sites. The downtime is defined as the ratio of hours not producing due to exceeding operating limits to total hours per year. 
Table 8. Capacity factor and downtime in function of hub acceleration and platform pitch limits for Costa Brava.

\begin{tabular}{|c|c|c|c|c|c|c|c|c|c|c|c|c|c|c|c|c|}
\hline & \multicolumn{8}{|c|}{$\begin{array}{c}\text { Capacity factor }(\%) \\
\text { Platform pitch }\left({ }^{\circ}\right)\end{array}$} & \multicolumn{8}{|c|}{$\begin{array}{c}\text { Downtime }(\%) \\
\text { Platform pitch }\left({ }^{\circ}\right)\end{array}$} \\
\hline & 0.5 & 1.0 & 2.0 & 3.0 & 4.0 & 5.0 & 6.0 & 7.0 & 0.5 & 1.0 & 2.0 & 3.0 & 4.0 & 5.0 & 6.0 & 7.0 \\
\hline 0.0 & 0.0 & 0.7 & 2.4 & 4.9 & 7.8 & 13.1 & 15.2 & 15.2 & 82.7 & 73.3 & 63.4 & 55.4 & 49.9 & 43.8 & 41.8 & 41.8 \\
\hline 1.0 & 0.0 & 0.8 & 2.7 & 5.8 & 10.8 & 29.3 & 33.9 & 33.9 & 81.9 & 71.7 & 60.6 & 50.7 & 42.2 & 23.1 & 18.5 & 18.5 \\
\hline 1.5 & 0.0 & 0.8 & 2.7 & 6.8 & 15.3 & 36.8 & 41.7 & 41.7 & 81.9 & 71.6 & 60.4 & 49.5 & 37.6 & 15.6 & 10.8 & 10.8 \\
\hline 2.0 & 0.0 & 0.8 & 2.7 & 6.8 & 17.8 & 39.4 & 44.3 & 44.3 & 81.9 & 71.6 & 60.4 & 49.4 & 35.1 & 13.1 & 8.3 & 8.3 \\
\hline & 0.0 & 0.8 & 2.7 & 9.1 & 22.8 & 44.7 & 49.6 & 49.6 & 81.9 & 71.6 & 60.1 & 45.5 & 28.6 & 6.3 & 1.5 & 1.5 \\
\hline$\stackrel{0}{\circlearrowright} 4.0$ & 0.0 & 0.8 & 2.7 & 9.1 & 22.8 & 44.7 & 49.6 & 49.6 & 81.9 & 71.6 & 59.2 & 44.2 & 27.3 & 5.0 & 0.2 & 0.2 \\
\hline $\begin{array}{l}\mathcal{U} \\
\mathcal{E}\end{array} 5.0$ & 0.0 & 0.8 & 2.7 & 9.1 & 22.8 & 44.7 & 49.6 & 49.6 & 81.9 & 71.6 & 59.0 & 44.0 & 27.1 & 4.8 & 0.0 & 0.0 \\
\hline$\stackrel{0}{\Rightarrow} 6.0$ & 0.0 & 0.8 & 2.7 & 9.1 & 22.8 & 44.7 & 49.6 & 49.6 & 81.9 & 71.6 & 59.0 & 44.0 & 27.1 & 4.8 & 0.0 & 0.0 \\
\hline 7.0 & 0.0 & 0.8 & 2.7 & 9.1 & 22.8 & 44.7 & 49.6 & 49.6 & 81.9 & 71.6 & 59.0 & 44.0 & 27.1 & 4.8 & 0.0 & 0.0 \\
\hline
\end{tabular}

Table 9. Capacity factor and downtime in function of hub acceleration and platform pitch limits for Gulf of Maine.

\begin{tabular}{|c|c|c|c|c|c|c|c|c|c|c|c|c|c|c|c|c|}
\hline & \multirow{2}{*}{\multicolumn{8}{|c|}{$\begin{array}{c}\text { Capacity factor }(\%) \\
\text { Platform pitch }\left({ }^{\circ}\right)\end{array}$}} & \multirow{2}{*}{\multicolumn{8}{|c|}{$\begin{array}{c}\text { Downtime }(\%) \\
\text { Platform pitch }\left({ }^{\circ}\right)\end{array}$}} \\
\hline & & & & & & & & & & & & & & & & \\
\hline & 0.5 & 1.0 & 2.0 & 3.0 & 4.0 & 5.0 & 6.0 & 7.0 & 0.5 & 1.0 & 2.0 & 3.0 & 4.0 & 5.0 & 6.0 & 7.0 \\
\hline \multirow{9}{*}{ 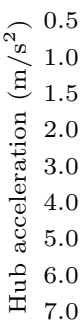 } & 0.0 & 0.4 & 1.3 & 2.9 & 5.1 & 9.5 & 11.0 & 11.0 & 91.9 & 86.6 & 81.5 & 76.7 & 72.8 & 68.0 & 66.5 & 66.5 \\
\hline & 0.0 & 0.7 & 2.3 & 5.5 & 10.8 & 28.2 & 34.0 & 34.0 & 86.1 & 76.9 & 67.6 & 58.2 & 49.3 & 31.0 & 25.4 & 25.4 \\
\hline & 0.0 & 0.8 & 2.5 & 6.1 & 14.1 & 39.0 & 46.4 & 46.5 & 85.7 & 75.2 & 65.1 & 54.6 & 42.7 & 16.9 & 9.8 & 9.8 \\
\hline & 0.0 & 0.8 & 2.5 & 6.1 & 14.1 & 40.9 & 48.8 & 48.8 & 85.7 & 75.2 & 65.0 & 54.5 & 42.6 & 15.0 & 7.4 & 7.4 \\
\hline & 0.0 & 0.8 & 2.6 & 6.7 & 17.6 & 45.6 & 53.8 & 53.8 & 85.6 & 74.8 & 64.2 & 52.8 & 37.9 & 9.2 & 1.3 & 1.3 \\
\hline & 0.0 & 0.8 & 2.6 & 6.9 & 18.1 & 46.4 & 54.7 & 54.7 & 85.6 & 74.8 & 64.0 & 52.4 & 37.2 & 8.2 & 0.1 & 0.1 \\
\hline & 0.0 & 0.8 & 2.6 & 6.9 & 18.1 & 46.4 & 54.8 & 54.8 & 85.6 & 74.8 & 64.0 & 52.4 & 37.1 & 8.1 & 0.0 & 0.0 \\
\hline & 0.0 & 0.8 & 2.6 & 6.9 & 18.1 & 46.4 & 54.8 & 54.8 & 85.6 & 74.8 & 64.0 & 52.4 & 37.1 & 8.1 & 0.0 & 0.0 \\
\hline & 0.0 & 0.8 & 2.6 & 6.9 & 18.1 & 46.4 & 54.8 & 54.8 & 85.6 & 74.8 & 64.0 & 52.4 & 37.1 & 8.1 & 0.0 & 0.0 \\
\hline
\end{tabular}

The findings demonstrate that the capacity factor increases nonlinearly with higher threshold limits. The maximum capacity factor of $49.6 \%$ is reached at Costa Brava with a hub acceleration of $3 \mathrm{~m} / \mathrm{s}^{2}$ and a platform pitch of $6^{\circ}$, which is the same value as presented in Table 7 where no threshold limits have been considered. The downtime, on the other hand, decreases with increasing threshold limits towards zero. For example, by having the platform pitch threshold limit at $5^{\circ}$ and the hub acceleration limit at $3 \mathrm{~m} / \mathrm{s}^{2}$, the capacity factor decreases by $4.9 \%$ in comparison to no threshold limits at Costa Brava. The resulting energy loss is about $2.2 \mathrm{GWh}$ per year and the downtime has increased to $6.3 \%$. 
Table 10. Capacity factor and downtime in function of hub acceleration and platform pitch limits for West of Barra.

\begin{tabular}{|c|c|c|c|c|c|c|c|c|c|c|c|c|c|c|c|c|}
\hline & \multicolumn{8}{|c|}{$\begin{array}{l}\text { Capacity factor }(\%) \\
\text { Platform pitch }\left({ }^{\circ}\right)\end{array}$} & \multicolumn{8}{|c|}{$\begin{array}{c}\text { Downtime }(\%) \\
\text { Platform pitch }\left({ }^{\circ}\right)\end{array}$} \\
\hline & 0.5 & 1.0 & 2.0 & 3.0 & 4.0 & 5.0 & 6.0 & 7.0 & 0.5 & 0 & 2.0 & 3.0 & 4.0 & 5.0 & 6.0 & 7.0 \\
\hline 20. & 0.4 & 0.4 & 1.0 & 1.0 & 1.0 & 1.0 & 1.0 & 1.0 & 95.7 & 95.7 & 94.6 & 94.6 & 94.6 & 94.6 & 94.6 & 94.6 \\
\hline$\stackrel{\infty}{2} 1.0$ & 1.2 & 1.2 & 5.2 & 5.2 & 13.5 & 13.5 & 13.9 & 13.9 & 89.2 & 89.2 & 80.8 & 80.8 & 73.0 & 73.0 & 72.6 & 72.6 \\
\hline 1.5 & 1.8 & 1.8 & 10.6 & 10.6 & 25.9 & 25.9 & 28.8 & 28.8 & 84.1 & 84.1 & 65.3 & 65.3 & 50.9 & 50.9 & 48.2 & 48.2 \\
\hline 2.0 & 1.9 & 1.9 & 12.2 & 12.2 & 35.1 & 36.1 & 46.9 & 46.9 & 83.0 & 83.0 & 61.3 & 61.3 & 39.6 & 38.7 & 28.4 & 28.4 \\
\hline 3.0 & 1.9 & 1.9 & 12.6 & 12.6 & 39.7 & 53.1 & 67.5 & 67.5 & 82.7 & 82.7 & 60.2 & 60.2 & 34.6 & 21.8 & 8.3 & 8.3 \\
\hline 4.0 & 1.9 & 1.9 & 12.6 & 12.7 & 41.3 & 57.7 & 72.6 & 72.6 & 82.7 & 82.7 & 60.1 & 60.0 & 32.9 & 17.4 & 3.3 & 3.3 \\
\hline $\begin{array}{l}\breve{G} 5.0 \\
\end{array}$ & 1.9 & 1.9 & 12.6 & 12.7 & 41.6 & 58.8 & 74.7 & 74 & 82.7 & 82.7 & 60.1 & 59.9 & 32.5 & 16.2 & 1.2 & 1.2 \\
\hline$\stackrel{0}{7} 6.0$ & 1.9 & 1.9 & 12.6 & 12.7 & 41.6 & 58.8 & 74.7 & 74 & 82.7 & 82.7 & 60.1 & 59.9 & 32.4 & 16.2 & 1.2 & 1.2 \\
\hline 7.0 & 1.9 & 1.9 & 12.6 & 12.7 & 41.7 & 59.5 & 75.5 & 75.5 & 82.7 & 82.7 & 60.1 & 59.8 & 32.0 & 15.2 & 0.0 & 0.0 \\
\hline
\end{tabular}

According to the findings, Gulf of Maine and West of Barra sites present higher capacity factors, but require at the same time higher hub acceleration limits.

It is common practice in the wind industry to set an operational limit for the hub acceleration, which is related to the safety of the turbine components and is about $0.3 \mathrm{~g}\left(\approx 3 \mathrm{~m} / \mathrm{s}^{2}\right)[43]$. Likewise, there is a maximum angle of inclination, which corresponds to the pitch motion and depends largely on the type of FOWT. For instance, Xue [44] has proposed a limit for the inclination angle under the maximum mean wind turbine thrust force of up to $7^{\circ}$ for a Spar concept. Considering these parameters, one may find the technical limits for the performance of the FOWT. For instance, at Gulf of Maine a capacity factor of $53.8 \%$ and a downtime of $1.3 \%$ would be achievable. The parameters have not only importance for the control strategy but also are essential for the platform design [43]. For example, the maximum angle of inclination $\theta_{\max }$ is related to the minimum rotational stiffness $C_{55, \min }$ of the structure by the inclining moment $M_{I}$ as [45]:

$$
C_{55, \min }=\frac{M_{\mathrm{I}}}{\theta_{\max }}
$$


In general, the higher the rotational stiffness required, the more expensive the floating substructure will be. Hence, the aim would be to reduce it as much as possible [46]. However, a more rigid structure could be beneficial in harsh conditions such as at West of Barra, because it would permit a higher maximum angle of inclination and thus enable to extract energy from more extreme environmental conditions and increase the capacity factor. To resume, the optimal threshold limits should be a tradeoff between the maximal energy yield as well minimal downtime and technical feasible limits for a safe operation of the FOWT. This analysis may help to identify suitable threshold limits at design stage and for feasibility studies of different offshore locations.

\section{Conclusion}

In this paper, a methodology has been presented to obtain the dynamic response of a FOWT to different load cases and to assess its performance considering different wind and wave conditions. A simplified model has been built using MATLAB and the system response has been evaluated for the surge, heave and pitch motions. The results have been compared with FAST, which is a well-known complex tool to model and simulate wind turbines. An overall good agreement has been found in the comparison of the structural properties computed by both models. Furthermore, the main motions and system's dynamics could be captured by the simpler model with an acceptable accuracy. The power generated by the FOWT has been computed for an environment with regular waves and steady waves as well as a load case consisting of turbulent wind and irregular waves. It has been found that even for the most extreme wind and wave combination the power loss experienced by the FOWT is less than $1 \%$ or $1.1 \%$, respectively the load case studied. Furthermore, the performance of the FOWT has been evaluated for three offshore locations with their specific environmental conditions. Surge and pitch motions are governed by the mean wind speed, whereas the hub acceleration is influenced strongly by the wave height. 
The response in heave is only of small magnitude for all three locations, which is typical for a Spar-type FOWT. The peak response has been obtained for all three degrees of freedom at rated wind speed, when the controller starts to reduce the thrust coefficient. Among the offshore locations, the largest motions appear at West of Barra, where the harshest environmental conditions exist, with $29.5 \mathrm{~m}$ for surge and $5.9^{\circ}$ for pitch motion. The highest value for the hub acceleration has also been obtained at West of Barra with $6.6 \mathrm{~m} / \mathrm{s}^{2}$. Despite the large motions, no significant loss in energy generation for the FOWT has been found. The difference is smaller than $1 \%$ for all three sites.

The highest capacity factor has been reached at West of Barra with up to $75 \%$, which exceeds current bottom-fixed offshore wind farms. This large capacity factors demonstrate the high power performance of the OC3-Hywind Spar FOWT and also coincides with the values achieved by the Hywind floating wind farm. Besides that, it shows that floating offshore wind could be a suitable complement to base load power generation. Finally, a sensitivity analysis has been used to evaluate the effect of different threshold limits, such as hub acceleration and platform pitch, on the performance of the FOWT. Lowering the threshold limits in order to increase the safe operation of the FOWT results in a nonlinear decrease of the capacity factor and nonlinear increase of downtime. The optimal selection of threshold limits should be a tradeoff between system reliability and maximal energy generation.

\section{Acknowledgements}

This work was supported in part by the European Union Horizon 2020 programme under the grant agreement H2020-LCE-2014-1-640741. 


\section{References}

[1] WindEurope, Deep water: the next step for offshore wind energy, http://www.ewea.org/fileadmin/files/library/publications/ reports/Deep_Water.pdf, 2013.

[2] Carbon Trust, Floating offshore wind: market and technology review, https://www.carbontrust.com/media/670664/ floating-offshore-wind-market-technology-review.pdf, 2015.

[3] WindEurope, Floating Offshore Wind Vision Statement, https: //windeurope.org/wp-content/uploads/files/about-wind/reports/ Floating-offshore-statement.pdf, 2017.

[4] G. Benveniste, M. Lerch, M. de Prada Gil, D.2.2: LCOE tool description, technical and environmental impact evaluation procedure, Deliverable LIFES50plus, 2016.

[5] J. Jonkman, W. Musial, Offshore code comparison collaboration (OC3) for IEA Task 23 offshore wind technology and deployment, Technical Report NREL/TP-5000-48191, 2010.

[6] X. Shen, J. Chen, P. Hu, X. Zhu, Z. Du, Study of the unsteady aerodynamics of floating wind turbines, Energy 145 (2018) 793-809.

[7] R. Farrugia, T. Sant, D. Micallef, A study on the aerodynamics of a floating wind turbine rotor, Renewable Energy 86 (2016) 770-784.

[8] M. Shen, Z. Hu, G. Liu, Dynamic response and viscous effect analysis of a tlp-type floating wind turbine using a coupled aero-hydro-mooring dynamic code, Renewable Energy 99 (2016) 800-812.

[9] L. Sethuraman, V. Venugopal, Hydrodynamic response of a stepped-spar floating wind turbine: Numerical modelling and tank testing, Renewable Energy 52 (2013) 160-174. 
[10] B. Wen, X. Tian, X. Dong, Z. Peng, W. Zhang, Influences of surge motion on the power and thrust characteristics of an offshore floating wind turbine, Energy 141 (2017) 2054-2068.

[11] B. Wen, X. Dong, X. Tian, Z. Peng, W. Zhang, K. Wei, The power performance of an offshore floating wind turbine in platform pitching motion, Energy 154 (2018) 508-521.

[12] T. Sant, K. Cuschieri, Comparing three aerodynamic models for predicting the thrust and power characteristics of a yawed floating wind turbine rotor, Journal of Solar Energy Engineering 138 (3) (2016) 031004.

[13] M. Martini, R. Guanche, J. Armesto, I. Losada, C. Vidal, Met-ocean conditions influence on floating offshore wind farms power production, Wind Energy 19 (3) (2016) 399-420.

[14] J. Jonkman, Definition of the Floating System for Phase IV of OC3, Technical Report NREL/TP-500-47535, 2010.

[15] J. Jonkman, S. Butterfield, W. Musial, G. Scott, Definition of a 5-MW reference wind turbine for offshore system development, Technical Report NREL/TP-500-38060, 2009.

[16] D. Matha, J. Cruz, M. Masciola, E. Bachynski, M. Atechson, A. Goupee, S. Gueydon, A. Robertson, Floating Offshore Wind Energy: The Next Generation of Wind Energy, Springer, 2016, Ch. Modelling of Floating Offshore Wind Technologies, pp. 133-240.

[17] C. Curfs, Dynamic behaviour of floating wind turbines: A comparison of open water and level ice conditions, Master Thesis Delft University of Technology, 2015.

[18] M. Karimirad, T. Moan, A simplified method for coupled analysis of floating offshore wind turbines, Marine Structures 27 (1) (2012) 45-63. 
[19] L. Cradden, P. Laporte Weywada, M. Atcheson, Floating Offshore Wind Energy: The Next Generation of Wind Energy, Springer, 2016, Ch. The Offshore Environment, pp. 21-86.

[20] F. Bianchi, H. de Battista, R. Mantz, Wind Turbine Control Systems: Principles, Modelling and Gain Scheduling Design, Springer, 2006.

[21] M. Borg, H. Bredmose, Dynamic analysis, Technical University of Denmark, PhD Summer School lecture: Analysis, Design and Testing of Floating Offshore Wind Turbine Structures (2017).

[22] F. Nielsen, T. Hanson, B. Skaare, Integrated dynamic analysis of floating offshore wind turbines, Proceedings of the 25th International Conference on Offshore Mechanics and Arctic Engineering, 2006, pp. 671-679.

[23] T.-T. Tran, D.-H. Kim, The platform pitching motion of floating offshore wind turbine: A preliminary unsteady aerodynamic analysis, Journal of Wind Engineering and Industrial Aerodynamics 142 (2015) 65-81.

[24] J. Jonkman, Dynamics modeling and loads analysis of an offshore floating wind turbine, Technical Report NREL/TLP-500-41958, 2007.

[25] M. Karimirad, Offshore energy structures: for wind power, wave energy and hybrid marine platforms, Springer, 2014.

[26] S. Chakrabarti, Handbook of Offshore Engineering, Elsevier, 2005.

[27] M. Masciola, J. Jonkman, A. Robertson, Implementation of a multisegmented, quasi-static cable model, Preprint NREL, 2013.

[28] M. Masciola, Instructional and Theory Guide to the Mooring Analysis Program, NREL, 2013.

[29] J. Jonkman, Inertial Moments of OC3-Hywind Components, https:// wind.nrel.gov/forum/wind/viewtopic.php?t=748, 2016. 
[30] E. Bachynski, T. Moan, Design considerations for tension leg platform wind turbines, Marine Structures 29 (1) (2012) 89-114.

[31] A. Robertson, F. Wendt, J. Jonkman, W. Popko, H. Dagher, S. Gueydon, J. Qvist, F. Vittori, J. Azcona, E. Uzunoglu, et al., OC5 project phase II: Validation of global loads of the DeepCwind floating semisubmersible wind turbine, Energy Procedia 137 (2017) 38-57.

[32] J. Jonkman, T. Larsen, A. Hansen, T. Nygaard, K. Maus, M. Karimirad, Z. Gao, T. Moan, I. Fylling, Offshore Code Comparison Collaboration within IEA Wind Task 23: Phase IV Results Regarding Floating Wind Turbine Modeling; Preprint, NREL/CP-500-47534, 2010.

[33] F. Driscoll, J. Jonkman, A. Robertson, S. Sirnivas, B. Skaare, F. Nielsen, Validation of a fast model of the statoil-hywind demo floating wind turbine, Energy Procedia 94 (2016) 3-19.

[34] S. Nallayarasu, N. Kumar, Experimental and numerical investigation on hydrodynamic response of buoy form spar under regular waves, Ships and Offshore Structures 12 (1) (2017) 19-31.

[35] D. Roddier, C. Cermelli, J. Weinstein, E. Byklum, M. Atcheson, T. Utsunomiya, J. Jorde, E. Borgen, Floating Offshore Wind Energy: The Next Generation of Wind Energy, Springer, 2016, Ch. State-of-the-Art, pp. 271332.

[36] Spanish Government - Ministry of Development, Puertos del Estado, http: //www.puertos.es/en-us/oceanografia/Pages/portus .aspx, 2018.

[37] P. Gomez, G. Sanchez, A. Llana, G. Gonzales, J. Berque, G. Aguirre, D.1.1 Oceanographic and meteorological conditions for the design, Deliverable LIFES50plus, 2015.

[38] M. Karimirad, T. Moan, Feasibility of the application of a spar-type wind turbine at a moderate water depth, Energy Procedia 24 (2012) 340-350. 
[39] T. Liu, X. Chen, J. Wu, K. Huang, Global performance and mooring analysis of a truss spar, in: Thirteenth International Offshore and Polar Engineering Conference, International Society of Offshore and Polar Engineers, 2003.

[40] World Energy Council, World Energy Resources Wind 2016, https ://www . worldenergy . org/wp-content/uploads/2017/03/ WEResources_Wind_2016.pdf, 2016.

[41] Statoil, World class performance by world's first floating wind farm, https : //www.statoil.com/en/news/15feb2018-world-class-performance. html, 2018.

[42] U.S. Energy Information Administration (EIA), Electric Power Monthly, https://www.eia.gov/electricity/monthly/current_month/epm.pdf, 2018.

[43] A. R. Nejad, E. E. Bachynski, T. Moan, On tower top axial acceleration and drivetrain responses in a spar-type floating wind turbine, in: ASME 2017 36th International Conference on Ocean, Offshore and Arctic Engineering, 2017.

[44] W. Xue, Design, numerical modelling and analysis of a spar floater supporting the DTU 10MW wind turbine, Master Thesis NTNU, 2016.

[45] M. Borg, M. Collu, A comparison between the dynamics of horizontal and vertical axis offshore floating wind turbines, Phil. Trans. R. Soc. A.

[46] A. Henderson, M. Collu, M. Masciola, Floating Offshore Wind Energy: The Next Generation of Wind Energy, Springer, 2016, Ch. Overview of Floating Offshore Wind Technologies, pp. 87-132. 